\title{
Quantitative methods in philosophy of language
}

\author{
Rafael Ventura
}

Bilkent University

\section{Correspondence}

Rafael Ventura, Department of Philosophy, Bilkent University, Ankara 06800 Turkey.

Email: rhtventura@gmail.com

\begin{abstract}
In this paper, I survey and defend the use of quantitative methods in philosophy of language. Quantitative methods in philosophy of language include a wide variety of methods, ranging from model-based techniques (computer simulations and mathematical models) to data-driven approaches (experimental philosophy and corpus-based studies). After offering a few case studies of these methodologies in action, I single out some debates in philosophy of language that are especially well served by their use. These are cases in which quantitative methods increase precision, improve the accuracy and reliability of results, and allow philosophers of language to borrow from other fields the best epistemic practices available. I conclude with some farreaching considerations about the role of qualitative and quantitative methods in debates about philosophical methodology.
\end{abstract}

\section{1 | INTRODUCTION}

A distinctive feature of philosophy is its heavy reliance on qualitative methods. These are methods that do not make use of mathematical tools, employing instead arguments formulated in natural languages. Take, for instance, Lewis' (1986) defense of modal realism. Lewis' main arguments draw on considerations of theoretical simplicity and on an analogy between possible worlds and other abstract entities, for example, sets in set theory. In his arguments, the tools of mathematics do not play any role. Or think of Kripke's (1980) causal theory of names. Kripke argues for his causal theory on the basis of thought experiments about reference. His arguments are also entirely qualitative. But these are not just any two examples: Lewis and Kripke are some of the most widely debated pieces in 20th century philosophy. Methodologically, they are also representative of a large portion of work in mainstream analytic philosophy that relies almost exclusively on qualitative tools of research.

However, exclusive reliance on qualitative methods can be pernicious. For one, it isolates philosophy from other disciplines. Scientists in both empirical and formal disciplines outside the philosophical ivory tower routinely employ 
mathematical tools. Disregard for these tools makes it difficult for philosophers to enter into a meaningful dialog with practitioners in other fields and borrow from them the best epistemic practices available. Given that it is now a commonplace in some corners of philosophy to echo Quine and claim that the discipline is continuous with the sciences, this methodological insularity is puzzling. What is more, philosophers' fondness for qualitative tools of research seems to clash with their professed commitment to analytic precision and clarity. In many cases, qualitative methods make philosophical discourse imprecise and unreliable, if not obscure and intractable.

Of course, this is not to say that qualitative methods can never be put to good use. But their hegemony does pose a serious problem in some areas of philosophy. As I show in this paper, this is often the case in philosophy of language. I then argue that an increasingly popular set of methods can help remedy this issue. These are methods that could be loosely called "quantitative." Quantitative methods comprise a wide variety of tools, ranging from model-based techniques (mathematical models and computer simulations) to data-driven approaches (experimental philosophy and corpus studies). This diversity notwithstanding, common to quantitative methods is the use of mathematical tools to formulate and solve philosophical problems.

Although logical tools are also common in philosophy of language, formal logic will not be discussed here. Logic has a long tradition of application to philosophical issues about language. By contrast, model-based and data-driven methods have only recently gained some prominence in philosophy of language. Moreover, these methods often have benefits that go beyond what logical tools can afford. In many cases, I shall argue, model-based and data-driven methods increase precision, improve the accuracy and reliability of results, and help debates in philosophy of language advance by making contact with relevant methods in neighboring disciplines.

Yet, despite these virtues, no study to date offers a comprehensive treatment of quantitative methods in philosophy of language. The present paper attempts to fill this gap by reviewing and defending the use of quantitative methods in some areas of philosophy of language. It proceeds as follows. In Sections 2 to 4, I begin by characterizing four quantitative methods: mathematical models, computer simulations, experimental philosophy, and corpus-based approaches. After offering a few illustrative examples of these methodologies in action, I then single out some debates in philosophy of language that are especially well served by their use. I conclude in Section 5 with some farreaching considerations about the role of qualitative and quantitative methods in debates about philosophical methodology.

\section{MATHEMATICAL AND COMPUTATIONAL MODELS}

Models are by far the least controversial quantitative tool currently in use in philosophy of language. A mathematical model employs mathematical operations to analyze relations between mathematical objects that are taken to represent a phenomenon of interest. Mathematical models are ubiquitous in the sciences, with a rich philosophical literature aiming to account for their nature and use-for an in-depth discussion, see Weisberg (2012). But models are also increasingly common in philosophy of language. Indeed, philosophers now routinely rely on algebra, probability theory, and differential equations to address key questions about language.

A particularly illuminating case is the debate on conventional meaning. On the basis of qualitative arguments, Quine (1936) famously challenged the view that conventional meaning could ever emerge in the absence of previously established conventions. Using simple models of signaling, however, Lewis (1969) showed that rational agents with no common language can imbue signals with conventional meaning. Although Lewis did not make extensive use of quantitative tools, his work has inspired a flurry of mathematical models. Culminating in Skyrms (2010), Lewis' sender-receiver model has been recast within the framework of evolutionary game theory. Evolutionary game theory typically employs differential equations to represent change over time in a population subject to natural selection and other evolutionary forces. Relying on differential equation models, Skyrms confirms that Quine's worry is not warranted: Conventional meaning arises spontaneously in the absence of pre-established conventions. These models 
also show that linguistic meaning arises not only among rational agents but also among agents devoid of a complex mental life through the action of blind variation and selection.

Alongside mathematical models, computational models are also quite widespread in philosophy of language. A computational model simulates a phenomenon of interest by representing a target system as a bundle of data stored in memory and algorithms-that is, update rules that govern the system's behavior. By iterating the update process in discrete time steps, the simulation yields data about the trajectory and end state of the system for further processing and analysis. Agent-based models are a particularly prevalent type of computer simulation, usually simulating interactions among autonomous or semi-autonomous agents. Regardless of their form, computer simulations often complement mathematical models by helping unravel the inner workings of systems that are too complex for analytical treatment.

For an oft-quoted example, consider Zollman's (2005) agent-based model for the emergence of linguistic meaning. His model represents a population of senders and receivers arranged on a torus-shaped landscape. Each agent is associated with a different strategy that specifies how the agent interacts with its neighbors. Some strategies are signaling strategies in that they differentiate between distinct signals, while others ignore the distinction and behave as if there were no signals. Agents get a payoff according to their own strategy and the strategies of those with whom they interact. On the basis of these payoffs, the model then simulates a process of social learning and cultural evolution: At the end of every round, each agent updates its strategy by imitating the strategy that yields the highest payoff in its neighborhood. As a result, high-performing strategies spread and low-performing ones go extinct. Zollman finds that this model gives rise to regional meaning-that is, agents come to associate the same signal with different meanings in different regions of the landscape.

Several authors have already pointed out continuities between modeling practices in the sciences and in philosophy more generally. For example, Paul (2012) and Godfrey-Smith (2012) argue that work in metaphysics should be construed as a form of modeling much like the practice of model building in the sciences. Williamson (2016) similarly sees work in some areas of philosophy as akin to modeling in the sciences and suggests that one important form of philosophical progress is the development of increasingly better models. Their point is thus that modeling practices in philosophy should be understood as part of a larger project that also includes models in the sciences.

But this leaves aside the question of how to justify the use of models in philosophy. Why should philosophers resort to mathematical and computational models? And under what conditions, if any, should they do so? Although it is difficult to answer these questions exhaustively, I propose here that models are especially useful when investigating phenomena that arise through biological and cultural evolution. This is because the primary agents of change in the biological and cultural realms are evolutionary causes, such as selection and drift. And whereas lengthy prose infused with qualitative arguments often struggles to track evolutionary processes across time, mathematical and computer models excel at it. Mathematical models use difference and differential equation to represent how populations change over time; computer simulations rely on simple update rules in discrete time steps to recreate the behavior of complex systems. This makes mathematical and computational models extremely illuminating tools to study a wide variety of phenomena that have traditionally puzzled philosophers, such as political organizations or the behavior of epistemic communities-for recent examples in these areas, see Bruner (2018) and Grim et al. (2019).

Given that languages are the product of biological and cultural evolution, it should come as no surprise that philosophy of language also stands to profit from the use of models. As the debate about conventional meaning indeed illustrates, models sometimes provide good results where verbal reasoning fails: In contrast to Quine's original worry, Lewis, Skyrms, and Zollman show that linguistic meaning can easily arise in the absence of pre-established conventions. It would have been extremely difficult (if not impossible) to track the rational decision-making and evolutionary processes thought to underlie the origin of communication and arrive at this conclusion without recourse to mathematical and computational tools. Models can therefore improve the reliability of philosophical investigations by furnishing philosophers of language with results that are not readily accessible through verbal reasoning alone.

A further benefit of models is due to their precision. Models in philosophy of language can, for example, specify the exact conditions under which conventional meaning should or should not be expected to emerge. This allows for 
fine-grained distinctions that would otherwise escape us. For instance, Grice (1975) suggests that his "cooperative principle" regulates conversational exchanges. But what exactly does he mean by "cooperation"? And how much of it is required for communication to take place? These are questions that Grice's verbal arguments are ill-equipped to answer but that mathematical models in pragmatics can grapple with more easily-for examples, see Franke, De Jager, and Van Rooij (2009) and Parikh (1991). Similarly, spatially explicit models of communication allow us to make precise claims about the conditions under which regional meaning should be expected to arise-namely, when the degree of population structure is sufficiently high. It would not be trivial, to say the least, to arrive at and justify these claims on the basis of purely qualitative methods.

Moreover, it is undeniable that both mathematical and computational models for the emergence of language trace back their origin to fields other than philosophy. Indeed, philosophers have largely borrowed these methods from fields such economics (in the case of rational choice theory) and evolutionary biology (as with evolutionary game theory). Considering how reliance on these methods has helped advance some debates in philosophy of language, their use therefore makes it especially salient that contact with methodologies from other disciplines can improve epistemic practices in philosophy.

\section{3 | EXPERIMENTAL PHILOSOPHY}

Another fairly common form of quantitative work in philosophy of language is experimental philosophy. Experimental philosophy typically borrows methods from the social sciences, especially linguistics and psychology, to probe subjects' responses to questions of philosophical interest. An extremely influential example is Knobe's (2003) finding in moral philosophy that subjects tend to think of an action as intentional depending on how they morally evaluate the consequences of that action. But influential examples also abound in other fields. In epistemology, for example, Weinberg, Nichols, and Stich (2001) rely on experimental data to argue that intuitions about what constitutes knowledge are unreliable as they vary with theory-irrelevant factors. And in philosophy of science, Stotz, Griffiths, and Knight (2004) analyze survey data to show that biologists have different concepts of what a gene is depending on their field of expertise.

In philosophy of language, a classic example of experimental philosophy is the treatment that Machery, Mallon, Nichols, and Stich (2004) give to Kripke's (1980) thought experiment. In Kripke's thought experiment, the person who we usually call Gödel and is commonly associated with having proven the incompleteness theorem did not in fact prove the theorem; it was actually a person called Schmidt who did. In their experiment, Machery and colleagues first presented participants with a vignette describing a case analogous to this thought experiment. Participants were then asked to indicate the referent of the name "Gödel." What they found is that judgments about reference are not stable across cultures: East Asians are significantly more likely than Americans to say in response to the thought experiment that "Gödel" does not refer to the person who usually goes by that name. Although this claim has not gone unchallenged (Deutsch, 2009; Martí, 2009; Sytsma \& Livengood, 2011), subsequent studies have for the most part replicated their initial results (Machery, Olivola, \& De Blanc, 2009; Machery, Sytsma, \& Deutsch, 2015).

Experimental philosophy has sparked a lively debate about whether philosophers should resort to intuitions at all and, if so, whether they should consult their own "expert" intuitions or that of experimental subjects. Two features of this debate are especially salient. One is their focus on whether appeals to intuitions, and of what type, are justified across the board. Another is the lack of a clear consensus: While one camp insists that philosophers do and should rely on intuitions (e.g., Ludwig, 2007), others continue to argue that philosophers are not justified in doing so (e.g., Weinberg, Gonnerman, Buckner, \& Alexander, 2010). ${ }^{1}$ But experimental methods can be and have been applied to a wide variety of contexts. Given that different questions may call for different methodologies, it is reasonable to suppose that attempts to justify experimental practices should take a more nuanced approach and proceed instead on a case-by-case basis. 
In line with this proposal, I isolate here some controversies within philosophy of language in which experimental methods hold great promise. For a start, consider debates in philosophy that turn on empirical claims about the linguistic behavior of competent speakers. As language users are not always capable of accurately intuiting and singlehandedly describing their linguistic behavior, testing these theories by restricting one's scope to the observation of a single individual is a notoriously inaccurate and unreliable procedure. By systematically probing and recording the linguistic behavior of several speakers at once, experimental philosophy therefore offers a promising way for philosophers of language to expand their pool of observations and respond to this concern. Of course, there is still a place for a close analysis of individual cases when addressing philosophical questions about language. But when it comes to empirical claims about the linguistic behavior of language users, philosophers of language can and should rely on experimental methods as well.

An example of this is the debate about the semantics of epistemic modals. A prominent theory about the semantics of epistemic modals claims that competent speakers evaluate epistemic modals according to the context of evaluation (Egan, Hawthorne, \& Weatherson, 2005). This claim clearly has empirical content: Whether competent speakers draw on contextual considerations to evaluate epistemic modals depends on how competent speakers in fact evaluate such modals. So experiments are appropriate in this case. Indeed, Knobe and Yalcin (2014) ran a series of experiments to test the theory, asking subjects to evaluate epistemic modals in different contexts. Contrary to expectation, their results indicate that competent speakers do not judge epistemic modals on the basis of contextsensitive factors. Their results therefore suggest that philosophers of language can more accurately answer the question of how speakers evaluate epistemic modals by observing the behavior of speakers in an experimental setting.

There are, however, considerable limitations to these experimental techniques. For one, experiments in philosophy usually rely on subjects' self-report and counterfactual judgment about what they would say or do in an imaginary situation. But as it has long been known to psychologists, we are not particularly good at introspecting and may therefore often mischaracterize both our actual and counterfactual reasoning (Nisbett \& Wilson, 1977). This therefore threatens to invalidate the use of protocols based on self-report and counterfactual judgment whenever the goal of experimental philosophy is to infer how we actually reason and behave. Fortunately, there are experimental methods that may be able to bypass this shortcoming. Instead of probing subjects for self-report and counterfactual thinking, behavioral studies (e.g., in economics) present participants with a concrete situation, prompt them to react to it, and observe their actual response. Behavioral studies therefore track how subjects actually behave, not what they say about their behavior is, was, or would be.

Motivated by similar considerations, some studies in philosophy of language are justified in taking a behavioral approach. Consider again the emergence of linguistic meaning. With few exceptions (Sandler, Meir, Padden, \& Aronoff, 2005; Senghas, 1995), meaning does not emerge de novo whenever speakers learn to communicate but is rather transmitted from language user to language user. This means that mechanisms for the emergence of meaning are opaque to language users, making it futile to expect participants in an experiment to provide reliable insights into how they work. To address this question, Bruner, O'Connor, Rubin, and Huttegger (2014) therefore turned to behavioral methods and recruited subjects to play different versions of the signaling game introduced by Lewis (1969). What they found is largely consistent with model predictions about the conditions under which linguistic conventions should be expected to emerge (Huttegger, Skyrms, Smead, \& Zollman, 2010). Using similar methods, Rubin et al. (manuscript) report results that likewise corroborate the predictions from models with partial conflict of interest (Zollman, Bergstrom, \& Huttegger, 2013).

Although this is still a nascent field, these experiments illustrate that methods from behavioral economics can help illuminate philosophically interesting features of language-for a recent defense of behavioral methods in philosophy of language, see Rubin, O'Connor, and Bruner (2019). Alongside other forms of experimental work in philosophy, these studies therefore also indicate that philosophers of language have a lot to gain by exploring methodologies from other fields. Be it to adjudicate on theories that make empirical claims about competent speakers or to circumvent limitations inherent to experimental techniques based on self-report, philosophers can and should familiarize themselves with methodologies that originate in other disciplines. 


\section{4 | CORPUS-BASED METHODS}

For all the recent attention that experimental philosophy has garnered, data-driven research in philosophy should not be restricted to experimental work. Corpus-based approaches in particular offer a series of advantages that make them an important complement to experimental tools. A corpus is simply a sample of spoken or written language that was not produced in a laboratory setting but rather collected in the "field"-that is, the tangle of human interactions that are mediated by linguistic exchanges. In contrast to the experimental data used in other forms of data-driven research, a corpus therefore consists in observational data.

In philosophy, corpus studies rely on corpus data to address questions of philosophical interest. An area that already makes particularly good use of these methods is the history and philosophy of science (Pence \& Ramsey, 2018). For example, Byron (2007) examines the occurrence of terms related to biology in a corpus of philosophy journals from the early 20th century to challenge the view that philosophy of biology emerged as a discipline only in the 1970s. Or consider Machery and Cohen (2011). Analyzing papers in the evolutionary behavioral sciences, they question a series of objections commonly raised against these disciplines-for example, that practitioners in these fields are poorly acquainted with evolutionary theory. Similarly, Overton (2013) employs text-mining techniques to investigate the plurality of explanatory practices in the sciences. And Wray (2010) and Weingart (2015) look at publication data to determine whether the history and philosophy of science forms a field distinct from philosophy of science.

But corpus methods also have tremendous potential when it comes to questions about language. In English, modern corpora go at least as far back as the beginnings of what is now known as the Brown corpus (Kucera \& Francis, 1967). Another watershed came with Godfrey, Holliman, and McDaniel's (1992) Switchboard corpus, the first large dataset of spoken and unscripted conversations. Together with associated tools, these datasets helped give rise to and shape the field of corpus linguistics-for a recent overview of questions and methods in this discipline, see Kennedy (2014). Research in corpus linguistics shows that results based on corpuses and experimental datasets sometimes diverge (Arppe \& Järvikivi, 2007; Hartford \& Bardovi-Harlig, 1992). This suggests that corpus studies and experimental techniques should complement each other when it comes to evaluating and improving both the accuracy and the reliability of our results.

Philosophers of language would therefore also do well to take into consideration linguistic corpuses alongside experimental data. Especially in the case of theories that make claims about our actual linguistic behavior, observational data in the form of linguistic corpuses can and should be brought to bear on theories in philosophy of language. Granted, in some cases it may be challenging to probe an immutable corpus for questions of philosophical interest. So philosophers may sometimes be better off studying instead language production elicited in the lab (Devitt, 2015). But in other cases, it may be possible to use corpus data to address questions that have long been of interest to philosophers.

Take, for example, long-standing debates in pragmatics about constative and performative functions of language that Austin (1965) helped initiate. By automatically tagging every utterance in the Switchboard corpus for its communicative function, Stolcke et al. (2000) were able to estimate the relative prevalence of different linguistic functions. One of their most surprising results is that only about a third of naturally occurring utterances purport to serve a constative function; almost a fifth is what they call "backchannel," linguistic expressions that simply signal to the interlocutor that one is listening. Clearly, this study does not settle disputes about how to understand assertions and performatives. But by proposing a distinction that can be operationalized, a corpus studies can offer a more precise answer than armchair speculation when dealing with related issues-for example, the question of how prevalent different functions of language actually are.

Another area in which corpus studies have a lot to offer is in recent debates about slurs. Some prominent theories about slurs claim that these terms convey their derogatory meaning by virtue of their semantic content (Hom, 2008). Appropriation, however, seems to pose a problem for content-based accounts of slurs: Slurs often lack their 
derogatory content when uttered by their usual targets. There is no shortage of proposals on offer about how to account for the shift in derogatory meaning that appropriation brings about (Anderson, 2018; Ritchie, 2017). Although these accounts should be evaluated on the basis of their philosophical merit, corpus studies could also help by appraising them against actual linguistic usage. For example, can slurs ever be offensive if uttered by their usual targets? And how often are slurs used in appropriated as opposed to offensive contexts? These are questions that have implications of philosophical significance but that are best addressed using corpus data.

In sum, there are some debates in which philosophers of language again stand to gain by attending to methodological insights from other disciplines. Yet, corpus studies remain unexplored in philosophy of language. With digital projects now making corpus data and analytical tools readily available, an increasingly large number of corpus studies addressing questions in philosophy of language should be expected to appear in coming years-for a recent defense of corpus methods and examples in different areas of philosophy, see Fischer and Curtis (2019).

\section{5 | CONCLUSION}

The present study offers a first attempt to map and defend the use of quantitative methods in philosophy of language. One upshot is that the success of quantitative methods in philosophy of language has been extremely diverse: While quantitative work has thrived in some debates, other ones have been largely untouched. It is also interesting to find variation across different methodologies: Model-based approaches are increasingly prevalent in some areas, while in others, it is data-driven research that carries the day. At a purely descriptive level, philosophy of language should therefore not be seen as a discipline that relies exclusively on qualitative methods. In addition to crafting and criticizing arguments, philosophers of language are at times in the business of building models and analyzing data.

There are also good normative reasons for thinking that philosophy of language has a lot to gain from quantitative methods. The tools of experimental and behavioral philosophy can offer important insights when assessing empirical claims about language. Likewise, corpus-based methods can bypass some of the limitations inherent to experimental and behavioral protocols when tackling these philosophical questions about language. And mathematical and computational models can offer a valuable perspective to study evolutionary phenomena of philosophical interest, such as linguistic behavior. When it comes to addressing these issues, the use of quantitative methods alongside qualitative ones should therefore continue.

For all the benefits associated with quantitative methods in philosophy of language, debates about philosophical methodology-in philosophy of language and beyond-have for the most part neglected the importance of these methods. Since the heyday of logical positivism, when Ayer (1946) argued that philosophy should be solely concerned with linguistic and logical facts, much of the debate in metaphilosophy has centered on the epistemic status of a priori and a posteriori methods-that is, methods that rely on reasoning and on sense experience. To this day, some continue to hold that a priori reasoning plays a fundamental role in philosophical discourse. Bealer (1996), for example, claims that a priori intuitions in philosophy are not only autonomous from empirical work in the sciences but also of greater epistemic value. But others vehemently reject this view. A recent example is Machery (2011), who contends that a priori intuitions derived from thought experiments are unreliable as thought experiments confront us with scenarios that are too fanciful and far-fetched.

However, the present study indicates that it may also be fruitful to classify philosophical methodologies along a different axis. As I have shown in this paper, some questions in philosophy of language require a quantitative treatment. But debates about the a priori and a posteriori fail to capture this, as the distinction between a priori and a posteriori methods is orthogonal to the distinction between quantitative and qualitative methods. To see this, consider again theories in philosophy of language that make empirical claims about the linguistic behavior of competent speakers. Clearly, empirical claims should be tested against data-be it by experimental, behavioral, or observational methods. These are methodologies that are both quantitative and a posteriori. By contrast, consider now debates about the evolution of linguistic meaning. When investigating evolutionary phenomena, dynamic models and 
computer simulations may be called for. In this case, the methodology is quantitative but a priori. So the distinction between quantitative and qualitative methods does not always coincide with the distinction between a priori and a posteriori methods.

These considerations have repercussions for debates about methodology not just in philosophy of language, but also in several other subdisciplines of philosophy. Indeed, other subdisciplines may also do well to consider the distinction between quantitative and qualitative methods, in addition to the distinction between model-based and data-driven approaches. In the face of numerous quantitative tools now at their disposal, this is also a reason for philosophers to pay more attention to these methods and learn how to benefit from them.

\section{ACKNOWLEDGEMENT}

I would like to thank Alex Rosenberg, Carlotta Pavese, Kevin Hoover, Robert Brandon, and Hannah Read for extremely helpful feedback on previous drafts of this paper.

\section{ENDNOTE}

${ }^{1}$ A minority position in this debate is that philosophers do not actually rely on intuitions, regardless of what they should do (e.g., Cappelen, 2012).

\section{ORCID}

Rafael Ventura (D) https://orcid.org/0000-0002-3708-4709

\section{REFERENCES}

Anderson, L. (2018). Calling, addressing, and appropriation. Bad Words, 6-28.

Arppe, A., \& Järvikivi, J. (2007). Every method counts: Combining corpus-based and experimental evidence in the study of synonymy. Corpus Linguistics and Linguistic Theory, 3(2), 131-159.

Austin, J. L. (1965). How to do things with words. Oxford: Oxford University Press.

Ayer, A. J. (1946). Language, truth and logic. London: Victor Gollancz.

Bealer, G. (1996). A priori knowledge and the scope of philosophy. Philosophical Studies, 81(2), 121-142. https://doi.org/10. 1007/BF00372777

Bruner, J., O'Connor, C., Rubin, H., \& Huttegger, S. M. (2014). David Lewis in the lab: Experimental results on the emergence of meaning. Synthese, 195(2), 603-621.

Bruner, J. P. (2018). Locke, Nozick and the state of nature. Philosophical Studies, 1-22. https://doi.org/10.1007/s11098018-1201-9

Byron, J. M. (2007). Whence philosophy of biology? The British Journal for the Philosophy of Science, 58(3), 409-422. https:// doi.org/10.1093/bjps/axm021

Deutsch, M. (2009). Experimental philosophy and the theory of reference. Mind \& Language, 24(4), 445-466. https://doi. org/10.1111/j.1468-0017.2009.01370.x

Devitt, M. (2015). Testing theories of reference. In J. Haukioja (Ed.), Advances in experimental philosophy of language (pp. 31-63). London and New York: Bloomsburry.

Egan, A., Hawthorne, J., \& Weatherson, B. (2005). Epistemic modals in context. In G. Preyer, \& G. Peter (Eds.), Contextualism in philosophy (pp. 131-170). Oxford: Oxford University Press.

Fischer, E., \& Curtis, M. (Eds.) (2019). Methodological advances in experimental philosophy. (pp. 175-208). London and New York: Bloomsbury.

Franke, M., De Jager, T., \& Van Rooij, R. (2009). Relevance in cooperation and conflict. Journal of Logic and Computation, 22(1), 23-54.

Godfrey, J. J., Holliman, E. C., \& McDaniel, J. (1992). SWITCHBOARD: Telephone speech corpus for research and development. Icassp, 517-520. IEEE.

Godfrey-Smith, P. (2012). Metaphysics and the philosophical imagination. Philosophical Studies, 160(1), 97-113. 
Grice, H. P. (1975). Logic and conversation. In P. Cole, \& J. Morgan (Eds.), Syntax and semantics (pp. 41-58). New York: Academic Press.

Grim, P., Singer, D., Bramson, A., Holman, B., McGeehan, S., \& Berger, W. (2019). Diversity, ability, and expertise in epistemic communities. Philosophy of Science, 86(1), 98-123. https://doi.org/10.1086/701070

Hartford, B. S., \& Bardovi-Harlig, K. (1992). Experimental and observational data in the study of interlanguage pragmatics. Pragmatics and Language Learning, 3, 33-52.

Hom, C. (2008). The semantics of racial epithets. The Journal of Philosophy, 105(8), 416-440. https://doi.org/10.5840/ jphil2008105834

Huttegger, S. M., Skyrms, B., Smead, R., \& Zollman, K. J. (2010). Evolutionary dynamics of Lewis signaling games: Signaling systems vs. partial pooling. Synthese, 172(1), 177-191. https://doi.org/10.1007/s11229-009-9477-0

Kennedy, G. (2014). An introduction to corpus linguistics. Routledge. https://doi.org/10.4324/9781315843674

Knobe, J. (2003). Intentional action and side effects in ordinary language. Analysis, 63(279), 190-194. https://doi.org/10. 1093/analys/63.3.190

Knobe, J., \& Yalcin, S. (2014). Epistemic modals and context: Experimental data. Semantics and Pragmatics, 7(10), 1-21.

Kripke, S. A. (1980). Naming and necessity. Cambridge: Harvard University Press.

Kucera, H., \& Francis, W. N. (1967). Computational analysis of present-day American English. Providence: Brown University Press.

Lewis, D. (1969). Convention: A philosophical study. Cambridge: Harvard University Press.

Ludwig, K. (2007). The epistemology of thought experiments: First person versus third person approaches. Midwest Studies in Philosophy, 31(1), 128-159. https://doi.org/10.1111/j.1475-4975.2007.00160.x

Machery, E. (2011). Thought experiments and philosophical knowledge. Metaphilosophy, 42(3), 191-214. https://doi.org/10. 1111/j.1467-9973.2011.01700.x

Machery, E., \& Cohen, K. (2011). An evidence-based study of the evolutionary behavioral sciences. The British Journal for the Philosophy of Science, 63(1), 177-226.

Machery, E., Mallon, R., Nichols, S., \& Stich, S. P. (2004). Semantics, cross-cultural style. Cognition, 92(3), B1-B12. https:// doi.org/10.1016/j.cognition.2003.10.003

Machery, E., Olivola, C. Y., \& De Blanc, M. (2009). Linguistic and metalinguistic intuitions in the philosophy of language. Analysis, 69(4), 689-694. https://doi.org/10.1093/analys/anp095

Machery, E., Sytsma, J., \& Deutsch, M. (2015). Speaker's reference and cross-cultural semantics. In On reference (pp. 62-76). https://doi.org/10.1093/acprof:oso/9780198714088.003.0004

Martí, G. (2009). Against semantic multi-culturalism. Analysis, 69(1), 42-48. https://doi.org/10.1093/analys/ann007

Nisbett, R. E., \& Wilson, T. D. (1977). Telling more than we can know: Verbal reports on mental processes. Psychological Review, 84(3), 231-259. https://doi.org/10.1037/0033-295X.84.3.231

Overton, J. A. (2013). "Explain" in scientific discourse. Synthese, 190(8), 1383-1405.

Parikh, P. (1991). Communication and strategic inference. Linguistics and Philosophy, 14(5), 473-514. https://doi.org/10. 1007/BF00632595

Paul, L. A. (2012). Metaphysics as modeling: the handmaiden's tale. Philosophical Studies, 160(1), 1-29. https://doi.org/10. 1007/s11098-012-9906-7

Pence, C., \& Ramsey, G. (2018). How to do digital philosophy of science (forthcoming). Philosophy of Science, 85, 930-941. https://doi.org/10.1086/699697

Quine, W. V. (1936). Truth by convention. In O. H. Lee (Ed.), Philosophical Essays for A. N. Whitehead (pp. 90-124). New York: Longmans.

Ritchie, K. (2017). Social identity, indexicality, and the appropriation of slurs. Croatian Journal of Philosophy, 17(2 (50)), 155-180.

Rubin, H., Bruner, J., O'Connor, C., \& Huttegger, S. (2015). Communication without the cooperative principle: A signaling experiment. http://philsci-archive.pitt.edu/11664/

Rubin, H., O'Connor, C., \& Bruner, J. (2019). Experimental economics for philosophers. In E. Fischer, \& M. Curtis (Eds.), Methodological advances in experimental philosophy. (pp. 175-208). London and New York: Bloomsbury

Sandler, W., Meir, I., Padden, C., \& Aronoff, M. (2005). The emergence of grammar: Systematic structure in a new language. Proceedings of the National Academy of Sciences, 102(7), 2661-2665. https://doi.org/10.1073/pnas.0405448102

Senghas, A. (1995). Children's contribution to the birth of Nicaraguan sign language. Cambridge, MA: Massachusetts Institute of Technology.

Skyrms, B. (2010). Signals: Evolution, learning, and information. Oxford: Oxford University Press. https://doi.org/10.1093/ acprof:oso/9780199580828.001.0001

Stolcke, A., Ries, K., Coccaro, N., Shriberg, E., Bates, R., Jurafsky, D., ... Meteer, M. (2000). Dialogue act modeling for automatic tagging and recognition of conversational speech. Computational Linguistics, 26(3), 339-373. https://doi.org/10. 1162/089120100561737 
Stotz, K., Griffiths, P. E., \& Knight, R. (2004). How biologists conceptualize genes: an empirical study. Studies in History and Philosophy of Science Part C: Studies in History and Philosophy of Biological and Biomedical Sciences, 35(4), $647-673$. https://doi.org/10.1016/j.shpsc.2004.09.005

Sytsma, J., \& Livengood, J. (2011). A new perspective concerning experiments on semantic intuitions. Australasian Journal of Philosophy, 89(2), 315-332. https://doi.org/10.1080/00048401003639832

Weinberg, J. M., Gonnerman, C., Buckner, C., \& Alexander, J. (2010). Are philosophers expert intuiters? Philosophical Psychology, 23(3), 331-355. https://doi.org/10.1080/09515089.2010.490944

Weinberg, J. M., Nichols, S., \& Stich, S. (2001). Normativity and epistemic intuitions. Philosophical Topics, 29(1/2), 429-460. https://doi.org/10.5840/philtopics2001291/217

Weingart, S. B. (2015). Finding the history and philosophy of science. Erkenntnis, 80(1), 201-213. https://doi.org/10.1007/ s10670-014-9621-1

Weisberg, M. (2012). Simulation and similarity: Using models to understand the world. Oxford: Oxford University Press.

Williamson, T. (2016). Model-Building in Philosophy. In R. Blackford, \& D. Broderick (Eds.), Philosophy's future: The problem of philosophical Progress (pp. 159-171). Malden: John Wiley \& Sons.

Wray, K. B. (2010). Philosophy of science: What are the key journals in the field? Erkenntnis, 72(3), 423-430. https://doi. org/10.1007/s10670-010-9214-6

Zollman, K. J. (2005). Talking to neighbors: The evolution of regional meaning. Philosophy of Science, 72(1), 69-85. https:// doi.org/10.1086/428390

Zollman, K. J., Bergstrom, C. T., \& Huttegger, S. M. (2013). Between cheap and costly signals: The evolution of partially honest communication. Proceedings of the Royal Society B: Biological Sciences, 280(1750), 1-1750.

\section{AUTHOR BIOGRAPHY}

Rafael Ventura received his PhD from Duke University in 2018. He is currently an Assistant Professor at Bilkent University. His work falls primarily within philosophy of science, philosophy of biology, and philosophy of language. He also has interests in epistemology and metaphilosophy.

How to cite this article: Ventura R. Quantitative methods in philosophy of language. Philosophy Compass. 2019;14:e12609. https://doi.org/10.1111/phc3.12609 